\title{
Lipoblastoma in Paediatric Tumour-report of Two Cases
}

\section{Majethia NK*}

Grant Medical College and Sir JJ Group of Hospitals, Maharashtra, India

\begin{abstract}
Lipoblastomatous tumours are rare neoplasms derived from embryonic white adipose tissues. We report on two children with different types of lipoblastomatous tumours at rare sites. The first had a localised lipoblastoma adjacent to the paraspinal muscles and spinal canal successfully resected without recurrence. The second patient had diffuse lipoblastomatosis in the axillary area. Radiologically, both lesions had characteristic fat density signals. The former lesion was benign-looking with a well-defined border, while the latter was infiltrative and had raised the suspicion of malignant liposarcoma. The definitive diagnosis was derived from characteristic histopathological features.
\end{abstract}

Keywords: Axillary mass; Childhood pathology; Infant; Lipoma; Lipoblastoma

\section{Introduction}

Adipose tissue tumours can be distinguished according to age and site in children. Lipoblastoma being the most commonly found in infants. Lipoblastoma is a rare benign mesenchymal tumor of embryonal fat, comprising of adipocytes and lipoblasts. It occurs in infants and young children (between 5 days to 6 years). Most common site of lipomatous tumor is subcutaneous tissue of the upper and lower extremities. Other sites are head and neck including spine, mediastinum, lungs, trunk, mesentery, peritoneal cavity, retro peritoneum and inguinal canal. Though it is a benign tumor, it may attain large size and cause compression symptoms, example if lesion is located near spinal cord patient presents with neurological symptoms. Cases are reported in literature with hemi paresis and lower limb paresis, otherwise it presents as a painless nodule or mass. There are 2 types of lipoblastoma. One is well encapsulated, superficial, solitary, subcutaneous, circumscribed, slow growing lesion and may mimic a lipoma. The other is deeper with an infiltrative growth pattern. It is sometimes referred to as Lipoblastomatosis, is multicentric, deepseated and ill-defined, diffuse lesion which arises in skeletal muscle, retro peritoneum, or mesentery. Lipoblastoma is definitively treated by complete resection [1]. Recurrence rates are reported in the range of $13 \%$ to $20 \%$. We report two cases of these rare lesions. The first one was a spinal/mediastinal lipoblastoma and the other an axillary lipoblastomatosis.

\section{Case History}

\section{Case 1}

18 months old male child came with complaints of incontinence and paraplegia since 7 months, other neurological findings were normal. MRI of the child showed a well-defined lobulated intradural extramedullary space occupying lesion extending from D11 to L4 vertebrae extending into paravertebral region (Figure 1). Surgical excision showed a fleshy mass arising from the subcutaneous tissue in the axilla, closely adherent to the muscles of the chest wall and the axillary neurovascular bundle. The mass was completely excised. We received multiple bits of tumor tissue bits measuring $(10.5 \times 5.1 \times 3.2)$ $\mathrm{cm}$, the external surface (Figure 2) of the tumor was capsulated. The cut surface of the tumor was characteristically glistening. Histological examination showed primitive mesenchymal cells, mature adipocytes, lipoblasts arranged in discrete lobules separated by fibro vascular septae. Post surgery patient was uneventful.

\section{Case 2}

2 years old female child came with a left axillary mass (Figure 3 ) since 1 year, on excising the lesion the tumor was measuring $(13.5 \times$ $6.5 \times 6.5) \mathrm{cm}$. The mass was non tender, soft to firm in consistency, bosselated surface, with no skin changes. The differential diagnoses included a vascular hamartoma, cystic hygroma, a soft tissue tumor

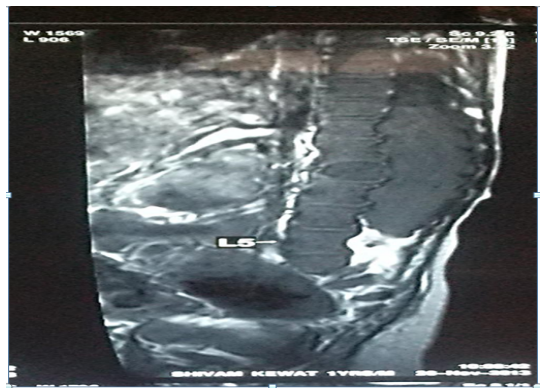

Figure 1: MRI- Intraduralextramedullary space occupying lesion extending from D11 to L4 vertebrae extending into paravertebral region.

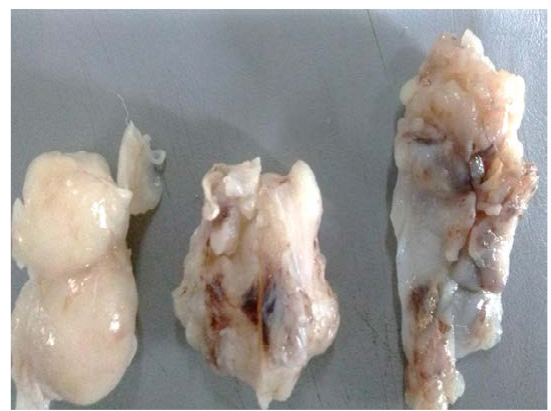

Figure 2: Tumour aggregating $(10 \times 5 \times 3) \mathrm{cm}$, E/S-capsulated, C/S-Yellowish white with glistening areas.

*Corresponding author: Majethia NK, Grant Medical College and Sir JJ Group of Hospitals, Maharashtra, India, Tel: 02223735555; E-mail: nikhilmajethia@gmail.com

Received December 23, 2015; Accepted February 17, 2016; Published February 27, 2016

Citation: Majethia NK (2016) Lipoblastoma in Paediatric Tumour-report of Two Cases. Med Rep Case Stud 1: 103. doi:10.4172/2572-5130.1000103

Copyright: (c) 2016 Majethia NK. This is an open-access article distributed under the terms of the Creative Commons Attribution License, which permits unrestricted use, distribution, and reproduction in any medium, provided the original author and source are credited. 
such as lipoblastoma or a liposarcoma, or a matted lymph node mass. The histological examination revealed lipoblasts, adipocytes arranged in lobules separated by fibrous septae with myxoid stroma and multivacuolated lipoblasts with myxoid stroma. Post resection period was uneventful.

\section{Discussion}

The majority of soft-tissue tumours occurring in childhood are benign and of vascular or fibroblastic origin. Adipose tumours are relatively unusual, making up about $6 \%$ of soft-tissue neoplasms reported in the first 2 decades of life. Approximately two-thirds of these are simple lipomas, up to $30 \%$ are lipoblastomas and liposarcomas are very rare [2]. Lipoblastoma is a tumor of infancy, with $90 \%$ before 3 years of age and $40 \%$ in the first year of life. A male preponderance of 3: 1 has been noted. Though most commonly found in the extremities $-70 \%$, it can also be seen in the head and neck area, trunk, mediastinum, retroperitoneum, and various organs like lung, heart and parotid gland [2]. Although benign in nature, lipoblastoma bears a striking histologic similarity to myxoid liposarcoma, a low-grade malignant tumour that is rare in childhood. Microscopically, Lipoblastoma can

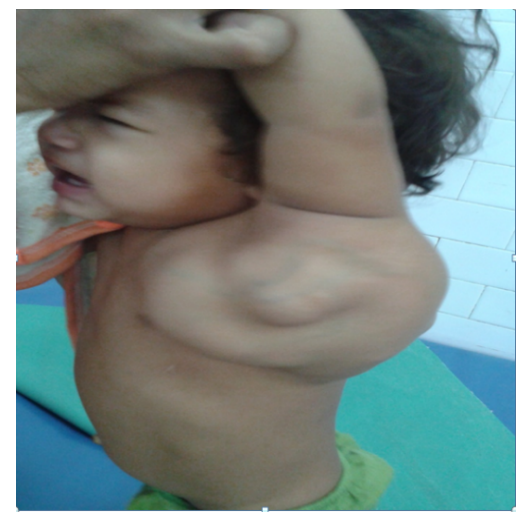

Figure 3: Axillary mass in a 1.5 year old female.

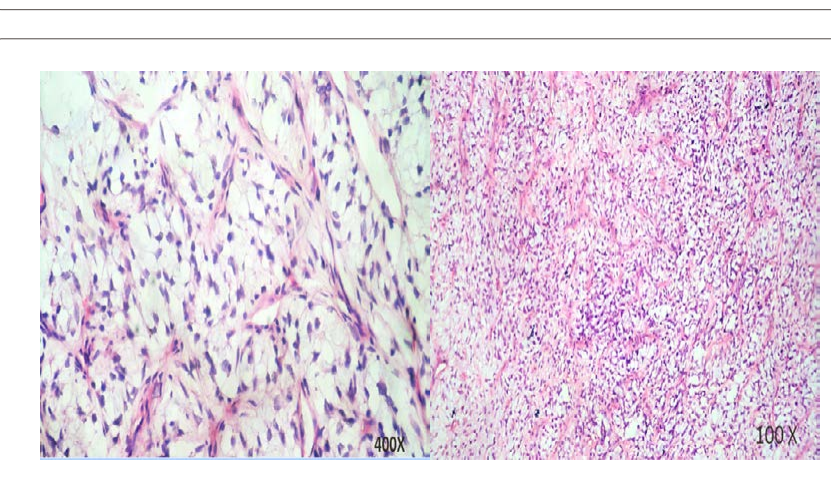

(A)

(B)

Figure 4: $A$ and $B$ represents Primitive mesenchymal cells, mature adipocytes, lipoblasts arranged in discrete lobules separated by fibrovascularseptae. be indistinguishable from myxoid liposarcoma. Clinically, the tumours often behave in a similar fashion. Traditionally, pathologists have used the patient's age to differentiate these neoplasms. Diagnostic imaging studies are invaluable in the preliminary diagnosis of fatty tumors. Plain X-rays and computed tomography scan can suggest the fat density of the tumor. Results of ultrasonography examinations can be confusing. The MRI is the most reliable method showing location, size, extent and mass characteristics of the tumor suggesting the histological components [3].

The present study we came across two cases of Lipoblastomaous tumors, both had similar gross appearance with soft sometimes fluctuant myxoid or gelatinous like areas. Histologically the lipoblastomas were characterized by lobules of mature and immature fat cells, primitive mesenchymal cells (Figures 4 and 5) and monovacuolar and multivacuolar lipoblasts (Figure 6). The lobules were separated by fibrous trabeculae containing small blood vessels. The differential diagnosis of lipomatous tumors is shown in Tables 1 and 2 [3].

\section{Conclusion}

Lipoblastomaous tumors are poorly understood and uncommon

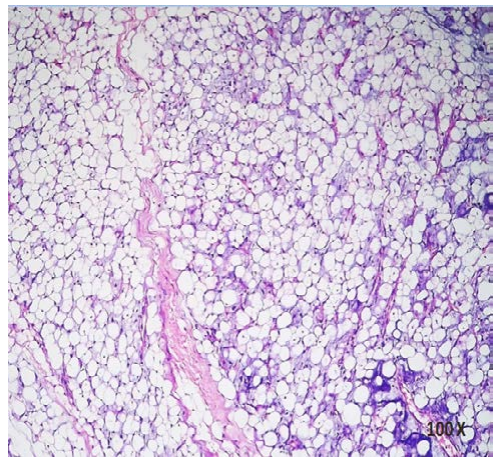

Figure 5: Lipoblasts, adipocytes arranged in lobules separated by fibrous septae with myxoidstroma.

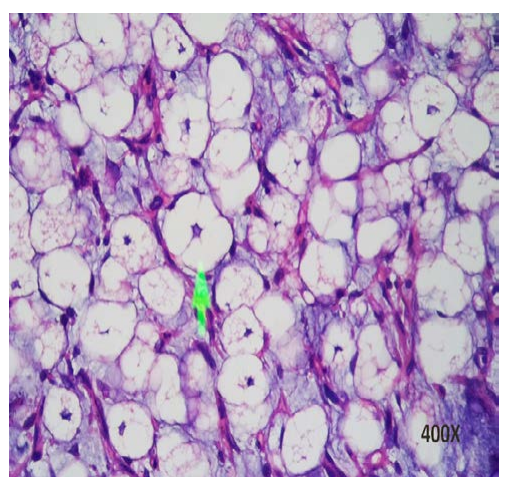

Figure 6: Histologically the lipoblastom as were characterised by monovacuolar and multivacuolarlipoblasts.

\begin{tabular}{|l|l|}
\hline Lipoma & Vacuoles may be seen in the adipocytes of conventional lipomas, the extent of vacuolated adipocytes is greater in number and smaller. \\
\hline $\begin{array}{l}\text { Hibernoma } \\
\text { (Brown fat tumor) }\end{array}$ & $\begin{array}{l}\text { Hibernoma cells differ from lipoblasts as they usually show a lobular pattern and central nucleus and abundant finely granular or } \\
\text { microvaculated cytoplasm with no myxoid matrix and less capillaries. }\end{array}$ \\
\hline Liposarcoma & $\begin{array}{l}\text { Non lobular pattern, plexiform capillary network, fetal fat cells with mitotic figures, hyperchromasia, nuclear atypia and myxoid } \\
\text { background. }\end{array}$ \\
\hline Lipoblastoma & $\begin{array}{l}\text { Well localized, non-malignant, rapidly growing, lobules of mature and immature fat cells, primitive mesenchymal cells, and monovacuolar } \\
\text { and multivacuolar lipoblasts. }\end{array}$ \\
\hline
\end{tabular}

Table 1: Diagnosis of lipomatous tumors. 
Page 3 of 3

\begin{tabular}{|c|c|c|c|c|}
\hline S. no & Study & Age/Sex & Site & Size $(\mathrm{cm})$ \\
\hline 1 & Liu et al., 175 Hospital of PLA Fujian Province, China [4]. & 3 years/male & Perineum & $4.5 \times 3.5 \times 2.5$ \\
\hline 2 & Krishnan et al., Lilavati Hospital, Mumbai [3]. & 8 month/Female & Axilla & $8 \times 7 \times 4.5$ \\
\hline 3 & Carlos Eduardo Molinari Nardi et al., Hospital Ana Costa, Santos, SP, Brazil [2]. & 12 months/Male & Cervical mass & $6 \times 4$ \\
\hline \multirow[t]{2}{*}{4} & \multirow[b]{2}{*}{ Rasalkar et al., Prince of Wales Hospital, Shatin, Hong Kong [5]. } & 14 years/female & Lower abdomen & \\
\hline & & 1.5 years/female & $\begin{array}{c}\text { Buttock, } \\
\text { paravertebral } \\
\text { areas }\end{array}$ & 7 \\
\hline 5 & Sinha et al., Tribhuvan University Teaching Hospital, Maharajgunj, Kathmandu, Nepal [6]. & 22 month/male & Neck & 5 \\
\hline \multirow[t]{7}{*}{6} & \multirow{7}{*}{$\begin{array}{l}\text { Miller et al., Department of Pathology, University of British Columbia, British Columbia's } \\
\text { Children's Hospital, Vancouver, BC [1]. }\end{array}$} & 8.3 years/Male & Abdominal wall & 4 \\
\hline & & 1 month/Female & Buttock & 3.5 \\
\hline & & 9.6 Years/Male & Foot & 2.5 \\
\hline & & 2.2 Year/Female & Axilla & 6 \\
\hline & & 3 month/Male & Thorax & - \\
\hline & & 6 month/Female & Axilla & - \\
\hline & & 1.6 Year/Male & Buttock & 7.5 \\
\hline \multirow[t]{2}{*}{7} & \multirow{2}{*}{ Present case study } & 1.5 year/male & Paravertebral area & $10 \times 5 \times 3$ \\
\hline & & 1.5 year/female & Axilla & $13 \times 6 \times 6$ \\
\hline
\end{tabular}

Table 2: Shows comparative studies.

soft tissue tumour of infancy and early childhood. Though lipoblastoma is an uncommon childhood tumour, it should be taken into consideration as a differential diagnosis in pediatric age group. There is no clear diagnostic criteria for lipoblastoma, Its diagnosis should be made by their microscopical and histopathological features. Though benign, it gives great difficulty in its management, due to its extensions to different fascial planes. Surgical resection is the treatment of choice except in those infiltrating tumors. The aim of surgery is complete gross excision without sacrificing the surrounding vital structures or extirpation of tissue that could lead to major deformity. Incomplete gross excision, infiltrating LPB, is notorious for its recurrence. Hence, sequential close postoperative follow up with MRI is essential. A follow up of at least 2 years post operatively is recommended [2].

\section{References}

1. Grant G, Miller MD, Natalie L, Yanchar MD, James F, et al. (1998) Lipoblastoma and liposarcoma in children: An analysis of 9 cases and a review of the literature. Can J Surg 41: 455-458.

2. Krishnan J, Hathiramani V, Hastak M, Redkar RG (2013) Myxoid Lipoblastoma. Indian Pediatr 50: 603-605.

3. Nardi CEM, Barreto L, de Carvalho LV, Guimarães AV (2013) Cervica hibernoma and Lipoblastomatosis. Einstein 11: 111-113.

4. Liu Q, Xu Z, Mao S, Zeng R, Chen W, et al. (2014) Perineal lipoblastoma: a case report and review of literature. Int J Clin Exp Pathol 7: 3370-3374.

5. Rasalkar DD, Chu WCW (2010) Lipoblastomatous Tumours, a Rare Entity: Report of Two Cases in Children. J Hong Kong Col Radiol 13: 209-212.

6. Sinha BK, Thapa N, Banskota DK (2006) Lipoblastoma in head and neck- A rare childhood tumour. Kathmandu University Medical Journal 4: 94-97. 